\title{
Longitudinal Observation for the Resin-Bonded Bridges
}

\author{
Mariusz Pryliński \\ School of Dental Technology, Poznań/Poland \\ Correspondence to: Mariusz Prylinski \\ E-mail: prylinska@email.net.pl
}

Key words:

resin-bonded prosthesis, inlay, retention rate

\begin{abstract}
The objective of the study was to perform a long-term clinical evaluation of resin-bonded bridges. Tooth preparation was restricted to the enamel in both anterior and posterior teeth. The study evaluated 58 bridges made for 44 patients between 1985 and 2003 in the Prosthodontics Department of the Medical School in Poznań, Poland, and in a private practice. All of the bridges were prepared by one dentist, the author of this article. The success rate of these resin-bonded bridges was determined on the basis of the following factors: adequate function, integrity of the bonds, absence of marginal caries, and high degree of patient satisfaction. The average success rate over the 18 years of observation was $82.8 \%$, whereas the mean average time of the retention of the resin bonded bridges in the oral cavity was 6 years 8 months. Ten of the 58 bridges (116 abutments) were considered failures because of debonding or the need to carry out endodontic treatment due to caries. The average duration of the resin-bonded prostheses in the oral cavity was 5 years, 8 months. Resin-bonded bridges on anterior maxillary teeth do not disturb the occlusion or articulation, which widens their use to patients with a deep over-bite.
\end{abstract}

\section{Introduction}

Progress in adhesive technology has created the possibility of restoring single missing teeth with a method that allows minimal removal of tooth tissue. The resulting resin-bonded prostheses are characterized by their minimal tooth destruction, longevity and good aesthetics (1-7).

This long-term clinical study of resin-bonded bridges began in 1981 (8). The aim of the investigation was to compare the longevity of removable partial dentures seated on abutment teeth with the use of composite resin and that of conventional bridges. The results of the study suggest that a long-term retention might be difficult to predict as the values of retention coefficient show, fluctuating from $46.1 \%$ after eleven months to $92.2 \%$ after eleven years of observation $(3,8)$. Creugers and VanÅft Hof conducted a statistical meta-analysis of 25 different clinical studies and concluded that $74 \%$ of adhesive bridges will still remain in working order after four years of use ( 9 ). However, the results of the studies are difficult to compare directly for a variety of reasons, such as significant differences in preparation of abutment teeth, the use of various metal alloys, varied methods of treating the metal surfaces of the retentive elements as well as the discrepancy in research description and presentation of results. The purpose of our study was to conduct a long-term clinical evaluation of resin-bonded fixed prostheses. Our minimal preparations replaced the far more destructive pin-ledge and other macro-rest preparations formerly required for retentive purposes.

\section{Materials and Methods}

All of the patients in this study received resin-bonded fixed bridges whose retentive elements were metal wings. A significant feature of these retainers is that their preparation is confined to enamel only. A total of 95 bridges were provided for 81 patients over a period of 18 years, commencing in January 1985 . Of this number, 32 prostheses were made in the Prosthodontics Department of the Medical School in Poznań, Poland, and 63 were prepared in the author's private practice. All of the clinical preparations were made by one prosthodontist, the author. 37 patients did not attend regular check-ups over the years of the study and were therefore excluded from the survey.

A total of 58 prostheses seated in the remaining 44 patients who systematically came for regular examinations were evaluated. For those patients who could not be evaluated before the final evaluation in February 2003, the date of their last examination was established as the end of the observation period. All of the patients received a full clinical 
examination every six months and were questioned closely on their level of satisfaction with the prosthesis provided. The 58 bridges consisted of 176 units, 56 of 3 units each, and the remaining 2 consisted of 4 units, each of which restored missing first and second maxillary premolars. Of the 44 patients 27 women (61.4\%), and 17 men (38.6\%), and their ages were from 18 to 60 , with a mean age of 38 years. All of the restorations, including the guide planes of the wings, were seated on previously prepared and etched abutment teeth with a chemically cured composite, Evicrol (Spofa - Dental S. A., Czech Republic). This particular product was chosen because of its low viscosity, which facilitated rapid and accurate placement. The resin bonded inlay retainers were cast in Remanium CS alloy (Dentaurum, Pforzheim - Germany). The fit surfaces were air-abraded with 50 micron aluminium oxide applied for 1 minute and cleaned with ultrasound in a neutral detergent solution for 15 minutes. Prior to placement the restoration was rinsed with distilled water for 3 minutes and air-dried with air free from oil contamination. The prosthesis was then seated on the abutment teeth and held with moderate pressure for 2-3 minutes. After another 3 minutes, the exess bonding resin was removed with diamond drills (Edenta - Porcelain veneer kit) and polished with Kerr Luster Paste (Kerr Corporation Orange - USA) using a porcelain veneer kit (Edenta).

\section{Results}

Out of the 58 prostheses, which were in service for an average period of 6 years, 8 months, 48 received a positive evaluation for an overall success rate of $82.8 \%$ (Table 1 ).

10 restorations were regarded as failures due to total or partial loss of retention or the need for endodontic treatment of abutment teeth (Table 2). The mean time of placement in the oral cavity for these failed prostheses was 5 years, 8 months.

One bridge did not dislodge throughout the 15-year examination period, and 31 others did not become debonded throughout a period of observation ranging from 7 to 14 years. It is quite remarkable that some restorations were in service for longer than 9 years before they became debonded.

Table 1. Clinical retention rate of resin-bonded prostheses

\begin{tabular}{lccccccccccccccc}
\hline $\begin{array}{l}\text { Years of } \\
\text { observation }\end{array}$ & 1 & 2 & 3 & 4 & 5 & 6 & 7 & 8 & 9 & 10 & 11 & 12 & 13 & 14 & 15 \\
$\begin{array}{l}\% \text { retention } \\
\text { rate }\end{array}$ & 100 & 100 & 96.5 & 94.8 & 94.8 & 93.1 & 93.1 & 93.1 & 84.5 & 82.8 & 82.8 & 82.8 & 82.8 & 82.8 & 82.8 \\
$\begin{array}{l}\text { Number } \\
\text { of debonds }\end{array}$ & 0 & 0 & 2 & 3 & 3 & 4 & 4 & 5 & 9 & 10 & 10 & 10 & 10 & 10 & 10 \\
\hline
\end{tabular}

Table 2. Details of the 10 failed resin-bonded prostheses

\begin{tabular}{ccll}
\hline Year of placement & Restored tooth* & Retention period & Reasons for failure \\
\hline 1985 & 24 & 5 years, 5 months & secondary caries 15 \\
1988 & 46 & 2 years, 2 months & large amalgam restoration 47 \\
1988 & 35 & 7 years, 7 months & large amalgam restoration 36 \\
1990 & 14 & 8 years, 2 months & endodontic treatment needed 15 \\
1990 & 24,25 & 8 years, 2 months & endodontic treatment needed 26 \\
1990 & 16 & 9 years, 5 months & broken crown 15 \\
1993 & 15 & 9 years & broken crown 14 \\
1993 & 14 & 8 years, 8 months & broken crown 15 \\
1994 & 15 & 3 years, 7 months & broken crown 14 \\
1995 & 16 & 2 years, 11 months & secondary caries 17 \\
\hline
\end{tabular}

\footnotetext{
* International numbering system was used.
} 


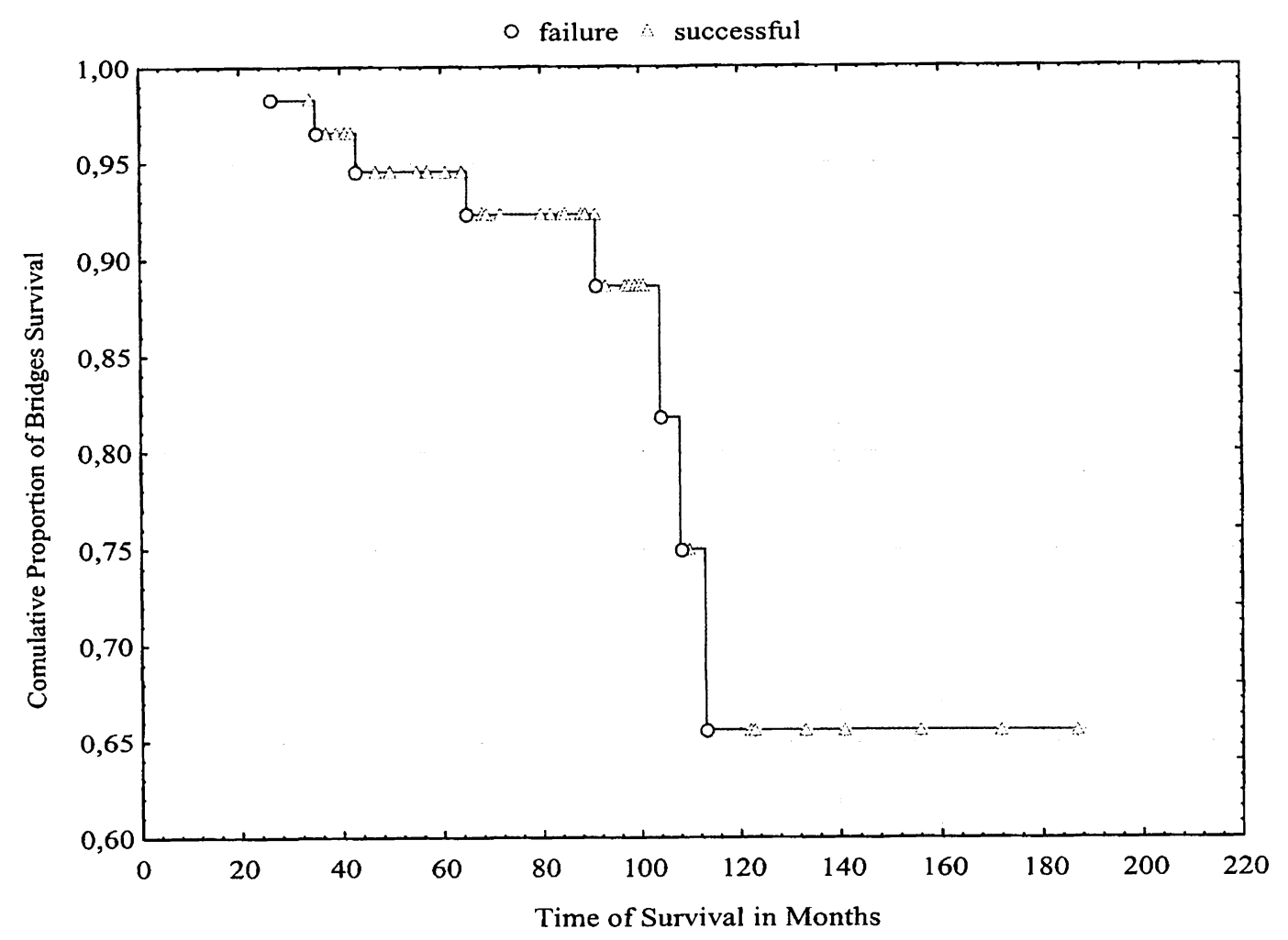

Fig. 1. Clinical survival of all resin-bonded bridges $(n=58)$ estimated by the Kaplan-Meier test.

Two restorations dislodged because of exessive movement of the abutments caused by existing periodontal disease, which led to the abutment teeth being extracted. These cases, judged on the basis of suggestions of Barrack and Bertz (8), were not regarded as failures in terms of prosthodontic treatment. Moreover, one of these prostheses remained in site for over 7 years ( 85 months) and the other for over 5 years (61 months).

Regular recording of the Gingival Index did not indicate any changes in the gingival condition of the patients who underwent the treatment. The supragingival location of the prostheses as well as the easy access for interproximal cleansing create favorable conditions for maintaining proper hygiene in the oral cavity. $(4-6,17)$.

All of the patients were fully satisfied with the aesthetics and comfort of their prostheses and were pleased that they were not removable.

\section{Discussion}

This longitudinal study provided definite clinical data regarding the retention rate of resin-bonded prostheses. Analysis of the cases that were considered failures showed that such cases were significantly reduced after 1995 , that is, 10 years after the introduction of the method of retention discussed here. This shows that the experience of the prosthodontist and careful selection of patients who qualify for prosthodontic treatment are the major factors determining its success, which is a conclusion that closely agrees with Priest and Barrack $(14,17)$.

The idea of minimal tooth preparation on small areas of the enamel of the abutment teeth as practiced earlier was later replaced by preparation of more of the tooth surface, i.e., an increase in the retention area. This contributes to a reduction in the fracture forces within the bonding layer, which favourably affects the longevity of the prostheses (17).

\section{Analysis of causes of failure}

In four cases during the period of the study the crown of an abutment tooth fractured, necessitating the removal of the prosthesis. All of these abutment teeth had been endodontically treated, and, as a result, their clinical crowns had very thin walls. Cast crown-root inlays were therefore, made and conventional 3-unit prostheses were provided.

In two other cases the bridge had to be removed to treat 
an abutment tooth or teeth endodontically. Both of these cases occurred in the same patient who had a three-unit prosthesis in the maxilla replacing the missing first right premolar and a four-unit prosthesis restoring the missing first and second left premolar. It is worth noting that both of the original prostheses remained in service for 8 years, 2 months.

Two bridges that dislodged were 3-unit prostheses that were restoring missing mandibular premolars. In both of these cases the abutment teeth had, at the time of bridge preparation, large amalgam restorations, which constituted a significant reduction in the area of enamel surface available for retention of the prosthesis.

The last two bridges perceived as failures were replacements for a missing first premolar and a first molar in the maxilla. After clinical examination carious lesions were discovered in the retention area of the prosthetic restorations. The development of this secondary caries caused loss of retention of the inlays and consequently led to their dislodgement. In one of these latter cases a resinbonded prosthesis that was remade is still in service after seven years, whereas, in the other case, a conventional bridge was provided.

The remaining 48 of the original 58 bridges constituted a success rate of $82.8 \%$ over an observation period of a maximum of 18 years (Fig. 1), which is comparable with previous findings. Barrack and Bertz $(8,17)$ observed 127 prosthetic restorations over a period of eleven years and reported a success rate of $92.9 \%$. Stokholm and Isidor (14), using a design similar to the one used by the author, reported a retention rate of $98 \%$ after a five-year period. The current study shows a retention rate of $94.8 \%$ (4 dislodgements) after a minimum 5- year period of observation. Williams et al. (18) having observed 99 restorations over a period of 10 years reported a dislodgement rate of $31 \%$. These authors, however, prepared restorations whose retentive elements were either perforated or with the retentive surface of the wings electrolytically etched. They concluded that both electrolytically etched and perforated restorations were characterized by a similar rate of debonding $(18,19)$. This finding might suggest that the resin bonding in this type of prosthetic restoration is based on mechanical retention between the bonding resin and the metal.

\section{Conclusion}

A clinical study conducted to evaluate the retention rate of resin-bonded prostheses, cemented with the low viscosity bonding agent Evicrol, over an 18-year period revealed a high success rate.

Analysis of the reasons for the failure of the few cases that were regarded as unsatisfactory led the author to the following conclusions:

1. The high rate of clinical retention $(82.8 \%)$ confirms the benefits of using low-viscosity bonding agents to seat resin-bonded prostheses on abutment teeth.

2. The amount of clinical experience of the prosthodontist and a thorough analysis of the arguments for and against this type of restoration are important factors determining the success of prosthodontic treatment when the resinbonded bridges are being used.

3. The placement of resin-bonded prostheses based on cast metal wings seated on anterior teeth in the maxilla does not create any obstruction to occlusion or articulation and thus widens the scope of the use of this particular method to include patients with a deep overbite.

\section{Acknowledgment}

I would like to thank Professor John Geoffrey Shaw for his invaluable editorial help with this article.

\section{References}

1. Creugers NH, Snoek PA, Vogels LM: Overconturing in resinbonded prostheses: Plaque accumulation and gingival health. J Prosthet Dent. 59: 17-21, 1988.

2. Howe DF, Denehy GE: Anterior fixed partial dentures utilizing the acid-etch technique and a cast metal framework, 37: 2831, 1997.

3. Hansson O: Clinical results with resin-bonded prostheses and adhesive cement. Quintessence Int, 25: 125-132, 1994.

4. Livaditis GJ: Etched-metal resin-bonded intracoronal cast restorations. Part I: The attachment mechanism. J Prosthet Dent, 56: 267-274, 1986.

5. Livaditis GJ: Etched-metal resin-bonded intracoronal cast restorations Part II: Design criteria for cavity prepararion. J Prosthet Dent, 56: 389-395, 1986.

6. Saunders WP: Resin bonded bridgework: A review J Dent, 17: 255-265, 1989.

7. Stokholm R , Isidor F: Resin-bonded inlay retainer prostheses for posterior teeth. A 5-year clinical study Int. J Prosthodont, 9: 161-166, 1966.

8. Barrack $G$, Bretz WA: A long-term prospective study of the etched-cast restoration. Int J Prosthodont, 6: 428-434, 1993. 
9. Creugers NHJ, Van't Hof MA: An analysis of clinical studies on resin-bonded bridges. J Dent Res, 70: 146-149, 1991.

10. Brabant A Indication and design: The key to successful resinbonded fixed partial dentures. Minimally invasive restorations with bonding. Quintessence Int, 28: 201-210, 1997.

11. Denehy GE: Cast anterior bridges utilizing composite resin. Pediatr Dent, 4: 44-47, 1982.

12. Hannson O, Bergstrom A: A longitudinal study of resin bonded prostheses. J Prosthet Dent, 76: 132-139, 1996.

13. Livaditis G J , Thompson VP: Resin-bonded cast restorations: clinical study. Int J Periodont Rest Dent, 4: 71-79, 1981.

14. Priest A: An eleven-year revaluation of resin-bonded fixed partial dentures. Int J Periodont Rest Dent, 15: 239-247, 1995.
15. Rammelsberg P, Pospiech P, Gernet W: Clinical factors affecting adhesive fixed partial dentures: A six year study. J Prosthet Dent, 70: 300-307, 1993.

16. Thompson VP, Livaditis GJ: Etched casting acid etch composite bonded posterior bridges. Pediatr Dent, 4: 38-43, 1982.

17. Barrack G: The etched cast restoration - clinical techniques and long-term results. Quintessence Int, 24: 701-713, 1982.

18. Williams VD, Theyer KE, Denehy GE: Cast metal resin bonded prostheses a 10-year retrospective study. J Prosthet Dent, 61: 436-441, 1993.

19. Hosseini A: Clinical evaluation of resin-bonded prostheses: Rochette technique Quintessence Int, 8: 567-571, 1994. 